\title{
Energetic analysis of rice production: A case study of Rohtak district in Haryana
}

Parmod Sharma, Y.K. Yadav, Kanishk Verma and Yadvika

Received : 04.01.2019; Revised : 02.03.2019; Accepted : 19.03.2019

See end of the Paper for authors' affiliation

Correspondence to :

Kanishk Verma

Department of Renewable and Bio-Energy Engineering, C.C.S. Haryana Agricultural University, Hisar (Haryana) India
ABSTRACT : Paddy covers approximately 40-45 per cent of the total area covered by cereal crops in India. Rice production needs to be augmented to meet the growing demand. Rice crop cultivated under watery condition either by storing canal water or pumping water or both, by utilizing a lot of electric/diesel energy especially when pumping is carried out. The amount of rice production is a direct function of energy inputs and outputs. The aim of this study was to examine the operation-wise and source-wise energy consumption pattern in rice crop production in western agro-climatic zone of Haryana. The data was collected through a questionnaire by face to face interviews. The amount of energy consumed in seedlings, land development, land preparation, transplanting, irrigation, weeding, fertilizer, harvesting and threshing and transportation were calculated for rice crop cultivation. The energy inputs in seed, human, diesel, electricity, machinery and fertilizer were taken into consideration to determine the source wise energy that was used in rice production. The average energy input of large farmers (LF), marginal farmers (MF) and small farmers (SF) was observed to be 35589.38, 35251.64 and 31432.07 MJ/ha, respectively while output energy was 144730, 166309 and $172180 \mathrm{MJ} /$ ha, respectively. Specific energy of small, medium and large category framers was $4.43,5.12$, and $6.25 \mathrm{MJ} / \mathrm{kg}$, respectively. The result revealed that fertilizer consumed highest energy in case of small farmers and on the other hand electricity consumed the bulk of energy in case of medium and large category of farmer. The result also showed that energy ratio, energy productivity and net energy gain of all category farmers were lie between 3.89 to 4.26 , 6.64 to $7.12 \mathrm{~kg} / \mathrm{MJ}$ and 89236.17 to $94073.10 \mathrm{MJ} / \mathrm{ha}$, respectively.

—KEY WORDS : Rice, Energy input, Energy output

-HOW TO CITE THIS PAPER : Sharma, Parmod, Yadav, Y.K., Verma, Kanishk and Yadvika (2019). Energetic analysis of rice production: A case study of Rohtak district in Haryana. Internat. J. Agric. Engg., 12(1) : 153-156, DOI: 10.15740/HAS/IJAE/12.1/153-156. Copyright@ 2019: Hind Agri-Horticultural Society. 